\title{
La valoración de arbolado en España. Una revisión
}

\author{
Fernando Vidal ${ }^{1}$
}

RESUMEN: En este trabajo se realiza una revisión de los principales métodos de valoración de arbolado empleados en España. La metodología se agrupa atendiendo a las principales utilidades del arbolado: frutal, forestal, medioambiental y ornamental. Se pretende ofrecer una panorámica sobre cuáles han sido y son las principales aplicaciones de dichos métodos y plantear cuáles son las principales líneas de trabajo futuras.

PALABRAS CLAVES: Arbolado, forestal, frutal, ornamental, valoración.

Clasificación JEL: Q10, Q51, Q57, L73.

DOI: 10.7201/earn.2012.01.05.

\section{Trees appraisal in Spain. A review}

\begin{abstract}
In this paper we review the main methods of tree appraisal used in Spain. Methods are grouped by major trees utilities: fruit, forestry, environmental and ornamental. We intend to offer an overview of which have been and are the main applications of these methods and suggest the main lines of future works.
\end{abstract}

KEYWORDS: Trees, forest, fruit, ornamental, appraisal.

JEL classification: Q10, Q51, Q57, L73.

DOI: 10.7201/earn.2012.01.05.

1 Departamento de Economía Agroambiental, I.C. y E.G.I. Universidad Miguel Hernández de Elche.

Agradecimientos: El autor agradece los comentarios de los revisores anónimos de la revista.

Dirigir correspondencia a: Fernando Vidal. E-mail: fvidal@umh.es.

Recibido en noviembre de 2010. Aceptado en febrero de 2012. 


\section{Introducción}

Aunque la valoración agraria se ha centrado en la valoración de fincas, incluidos los cultivos permanentes que sobre las mismas se han establecido, no es infrecuente que se plateen cuestiones relativas al valor del vuelo de una plantación. El presente trabajo se centra en aquellos casos en los que la valoración del arbolado es independiente del capital-tierra, es decir, del comúnmente conocido como valor del suelo. La valoración conjunta de ambos (suelo+vuelo) sería considerada, pues, como un caso más de la valoración de fincas.

Adoptaremos la división establecida por Caballer (1999), atendiendo a la utilidad de los árboles. Distinguiremos, así, entre árboles cuya utilidad es fácilmente traducible en términos monetarios, por su capacidad de generar rentas, básicamente por su componente frutal y/o forestal, y aquella otra utilidad más difícilmente traducible a términos económicos, al no generar rentas, en este caso su faceta medioambiental y/u ornamental. A nadie escapa que en múltiples ocasiones los árboles presentan diferentes utilidades, y por tanto, pueden y de hecho ocurre, presentar diferentes valores ante una tasación. Un árbol en una casa de campo puede ser valorado por su componente frutal (cosecha), forestal (madera, leña, etc.) u ornamental (embelleciendo con su presencia dicho jardín), sin olvidar los beneficios medioambientales que todo árbol supone. El valor final dependerá de las circunstancias particulares y del objeto de la valoración, predominando en cada caso una utilidad u otra.

Las aplicaciones de la valoración de arbolado son muy numerosas; desde las valoraciones motivadas por la expropiación debido a la construcción de líneas de alta velocidad, autovías o demás obras públicas, hasta las motivadas por daños de múltiples tipos: accidentes físicos, químicos, meteorológicos, incendios forestales, impacto ambiental, etc. También es cada vez más importante la concienciación que los poderes municipales presentan respecto al valor de los elementos integrantes de sus inventarios públicos, en particular de sus parques o jardines, especialmente hacia aquellos árboles que puedan tener la catalogación de históricos o monumentales.

Como se ha comentado, la valoración de arbolado se ha presentado comúnmente como un caso particular de la valoración de tierras y como tal aparecía en las obras dedicadas a la misma, comúnmente bajo el epígrafe de valoración de montes. Así, podemos ya encontrar apartados específicos dedicados a la misma en obras clásicas como las de Ruiz (1861), Museros (1871; 1877), Torrejón (1897; 1935), Sánchez (1915), Salazar (1922), Elorrieta (1947) o Santi (1952). También se repite este esquema en manuales más recientes, caso de los trabajos de Ruiz (1969; 1986), Caballer (1975; 1985), Olmeda et al. (1989), Ballestero (1991), Alonso e Iruretagoyena (1995), Guadalajara (1996), García (1998), Vidal et al. (2000), Vidal (2002), Humero (2006), Alonso y Serrano (2007) y Ortuño et al. (2007).

No es habitual encontrar una obra que recoja y sistematice exclusivamente la valoración de arbolado. Sin embargo, el profesor Caballer presenta en su obra "Valoración de Árboles" (Caballer, 1999) el primer tratado en el que se recoge exclusivamente la valoración del arbolado en su cuádruple vertiente: frutal, forestal, medioam- 
biental y ornamental. Se trata de un manual clave y de referencia en la materia. Otras obras genéricas sobre la valoración de arbolado, generalmente manuales empleados en cursos específicos sobre valoración de arbolado, serían las de Cardells y Salvador (2000), Gabaldón y Ribal (2000) o Vidal et al. (2001).

En los siguientes apartados se hará un repaso de los principales trabajos de valoración de arbolado en nuestro país, atendiendo a la cuádruple vertiente antes mencionada. Así, el apartado 2 se centrará en los trabajos que se han ocupado primordialmente de la componente frutal del arbolado, el apartado 3 de su utilidad forestal, mientras que el apartado 4 y 5 se ocuparán de los estudios que valoran la utilidad medioambiental y ornamental, respectivamente.

También se ha elaborado un cuadro resumen con parte de los trabajos analizados (Cuadro 1). Éste contiene información referida al bien o servicio valorado, la metodología empleada, la/s utilidad/es valorada/s y el valor obtenido, caso de estar disponible. Dada la limitación de espacio a la que nos obligan las normas de la revista, los trabajos se desarrollarán en uno sólo de los epígrafes, pese a que hayan sido valoradas más de una de sus utilidades, mostrándose, eso sí, todas ellas en dicho Cuadro 1. También se indicará en el mismo si la metodología empleada realiza una valoración sobre "el árbol" como individuo frente a aquellas que realizan una valoración sobre la "masa". Una panorámica de los métodos empleados en otros países y su relación con los aquí enumerados puede encontrarse en Caballer (1989a y 1999), Prieto et al. (1999), Caparrós et al. (2001 y 2007), Mogás y Riera (2001), Campos y Caparrós (2006), AEPJP (2007), Contato et al. (2008), Ovando et al. (2008) y LópezPeredo et al. (2009).

\section{CUADRO 1}

Trabajos sobre valoración de arbolado en España

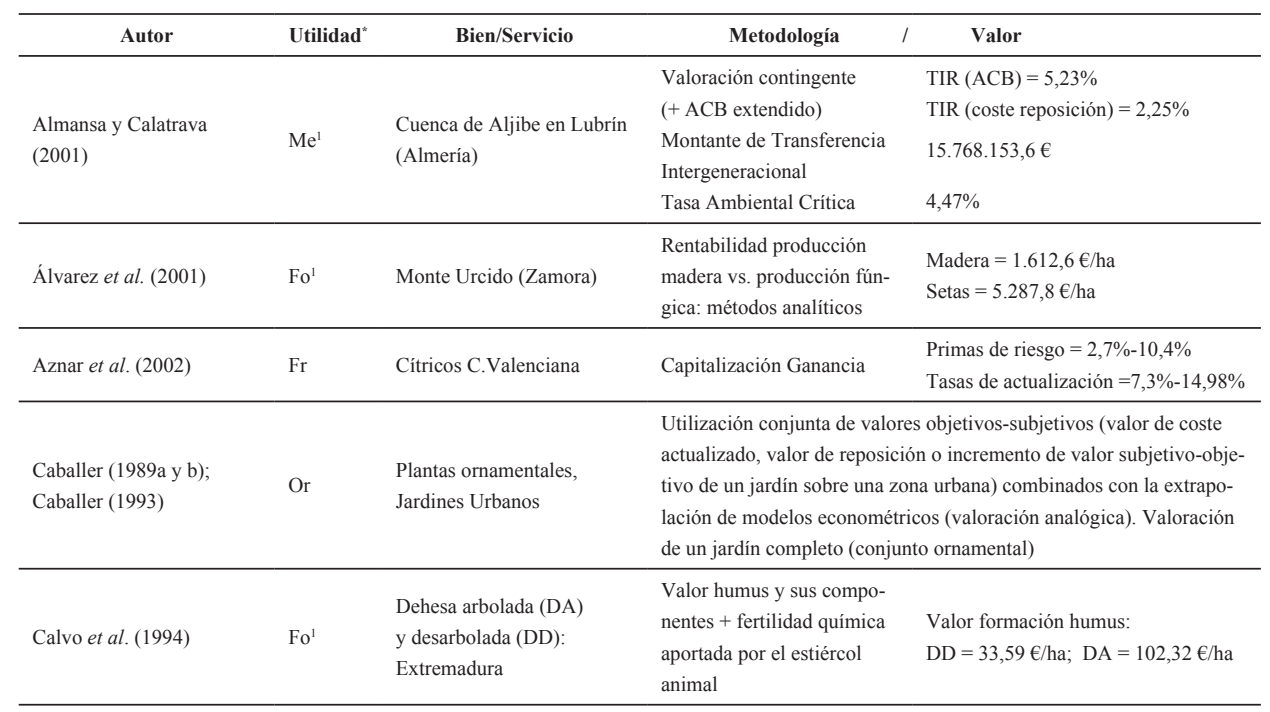




\section{CUADRO 1 (CONT.)}

\section{Trabajos sobre valoración de arbolado en España}

\begin{tabular}{|c|c|c|c|c|}
\hline Autor & Utilidad $^{*}$ & Bien/Servicio & Metodología & Valor \\
\hline \multirow[t]{2}{*}{ Campos (1994a) } & \multirow[t]{2}{*}{$\mathrm{Fo}, \mathrm{Me}^{\mathrm{l}}$} & \multirow[t]{2}{*}{$\begin{array}{l}\text { Alcornoques Montes de } \\
\text { Jerez de la Frontera (Cádiz) }\end{array}$} & $\begin{array}{l}\text { Valor Económico Total } \\
\text { (VET) parcial de una repo- } \\
\text { blación con alcornoques }\end{array}$ & $\begin{array}{l}\text { Valor comercial repoblación }>0 \\
\text { hasta tipo de interés del } 3 \% \text {. Si tasa } \\
\text { social de descuento }=6 \% \text {, la sociedad } \\
\text { aceptará repoblación si la ganancia } \\
\text { ambiental }>1.021,7 € / \text { ha repoblada. }\end{array}$ \\
\hline & & & $\begin{array}{l}\text { VET conservación de Mon- } \\
\text { tes de Jerez }\end{array}$ & VAN: $113,9 € /$ ha \\
\hline Campos (1994b) & $\mathrm{Fo}, \mathrm{Me}^{1}$ & $\begin{array}{l}\text { Dehesas y montados } \\
\text { (Península Ibérica) }\end{array}$ & $\begin{array}{l}\text { VET: Margen Neto de } \\
\text { Explotación (MNE) y Be- } \\
\text { neficios Ambientales Netos } \\
\text { (MNA) }\end{array}$ & $\begin{array}{l}\text { MNE }(€ / \text { ha })=[-35,5 ; 20,8] \\
\text { VAN }(€ / \text { ha })=[24,6 ; 178,4] \\
\text { Rentabilidad comercial }(\%)=[-1,4 ; 1] \\
\text { Rentabilidad privada }(\%)=[-14,7 ; 0,5]\end{array}$ \\
\hline Campos (1998b) & $\mathrm{Fo}, \mathrm{Me}^{1}$ & $\begin{array}{l}\text { Pino Piñonero y eucalipto } \\
\text { (P.N. Doñana) }\end{array}$ & \multicolumn{2}{|c|}{$\begin{array}{l}\text { Rentabilidad forestación sólo competitivas para tasas de descuento } \\
<4 \% \text {. } \\
\text { Rentabilidad forestación pino siempre menor que con eucalipto. }\end{array}$} \\
\hline Campos (1999) & $\mathrm{Fo}, \mathrm{Me}^{1}$ & $\begin{array}{l}\text { Dehesa Monfragüe } \\
\text { (Cáceres) }\end{array}$ & \multicolumn{2}{|c|}{$\begin{array}{l}\text { Renta de Bienestar Social (RTS): Sistemas normalizados de contabili- } \\
\text { dad nacional }(\mathrm{SCN}) \text { vs. sistema de cuentas agroforestales (CAF) } \\
\text { RTS ( sistema SCN) }=48 € / \text { ha; RTS (sistema CAF) }=306 € / \text { ha. }\end{array}$} \\
\hline Campos (2010) & Fo, Me & Ecosistemas naturales & \multicolumn{2}{|c|}{$\begin{array}{l}\text { Renta total social y VET a partir de un sistema de cuentas nacionales } \\
\text { verde (SCNV). El SCNV permite ofrecer múltiples indicadores sin- } \\
\text { gulares y de síntesis de su contribución económica total a la sociedad: } \\
\text { producción intermedia, producción final, renta del trabajo, renta de } \\
\text { capital, renta total, capital total y tasa de rentabilidad. }\end{array}$} \\
\hline Campos et al. (1996) & Fo, $\mathrm{Me}^{1}$ & $\begin{array}{l}\text { Dehesa Monfragüe } \\
\text { (Cáceres) }\end{array}$ & $\begin{array}{l}\text { Margen Neto Comercial } \\
\text { (MNC), VET. Escenarios: } \\
\text { Dehesa Arbolada (DA) y } \\
\text { Dehesa Desarbolada (DD) }\end{array}$ & $\begin{array}{l}\text { MNCDD }=14,3 € / \text { ha; } M N C D A=23,8 € / \text { ha } \\
\text { VET (Excedente Neto): } \\
\text { DA }=8,2-58,6 € / \text { ha; DD }=14,6-65,1 € / \text { ha }\end{array}$ \\
\hline Campos et al. (2008a) & $\mathrm{Me}^{1}$ & $\begin{array}{l}\text { P.N. Los Alcornocales } \\
\text { (Cádiz y Málaga) y pinares } \\
\text { silvestres de la Sierra } \\
\text { de Guadarrama } \\
\text { (Madrid y Segovia) }\end{array}$ & $\begin{array}{l}\text { Valor añadido neto am- } \\
\text { biental (VANA): privado } \\
\text { + público } \\
\text { Rentabilidad Total (RT): } \\
\text { comercial + ambiental }\end{array}$ & $\begin{array}{l}\text { P.N. Alcornocales } \\
\mathrm{VAN}_{\mathrm{A}}=215,25 € / \text { ha }(209,3 \text { privado }+ \\
5,95 \text { público }) . \mathrm{RT}=5,02 \%(2,89 \% \\
+2,13 \%) \\
\text { Sierra Guadarrama } \\
\mathrm{VAN}_{\mathrm{A}}=652,67 € / \text { ha }(432,06 \text { privado } \\
+220,61 \text { público }) \\
\mathrm{RT}=5,46 \%(2,03 \%+3,43 \%)\end{array}$ \\
\hline Campos y Caparrós (2006) & Fo, $\mathrm{Me}^{1}$ & $\begin{array}{l}\text { Pinar Sierra de Guadarrama } \\
\text { Dehesa Monfragüe } \\
\text { (Cáceres) }\end{array}$ & $\begin{array}{l}\text { CAF (sistema de cuentas } \\
\text { agroforestales): valores co- } \\
\text { merciales (madera y corcho, } \\
\text { VC) + valores ambientales } \\
\text { cuasi comerciales no ma- } \\
\text { dereros (caza, hongos,..., } \\
\text { VQC) + valor servicio am- } \\
\text { biental público (VA) } \\
\text { Tasa rentabilidad social } \\
\left(\mathrm{TR}_{\mathrm{S}} \text { ) y privada }\left(\mathrm{TR}_{\mathrm{p}}\right)\right.\end{array}$ & $\begin{array}{l}\text { Pinar }(€ / \text { ha })=V C: 182+\text { VQC: } 346+ \\
\text { VA: } 235=763 € / \text { ha } \\
\text { Dehesa }(€ / h a)=V C: 488+\text { VQC: } 132 \\
\text { + VA: } 17=637 € / \text { ha } \\
\text { Pinar: } \mathrm{TR}_{\mathrm{s}}=3,41 \% ; \mathrm{TR}_{\mathrm{p}}=4,74 \% \\
\text { Dehesa: } \mathrm{TR}_{\mathrm{S}}=8,74 \% ; \mathrm{TR}_{\mathrm{p}}=9,72 \%\end{array}$ \\
\hline Campos y Caparrós (2009) & $\mathrm{Fo}, \mathrm{Me}^{1}$ & $\begin{array}{l}\text { Pinos silvestres Sierra de } \\
\text { Guadarrama (PSG) } \\
\text { P.N. los Alcornocales } \\
\text { (PNA) }\end{array}$ & $\begin{array}{l}\text { CAF: valores comerciales } \\
\text { (VC) + valores ambienta- } \\
\text { les cuasi comerciales no } \\
\text { madereros (VQC) + valor } \\
\text { servicio ambiental público } \\
\text { (VA) }\end{array}$ & $\begin{array}{l}\text { PSG }(€ / \text { ha })=V C: 208+\text { VQA: } 393+ \\
\text { VA: } 267=867 € / \text { ha } \\
\text { PNA }(€ / \text { ha })=\text { VC: } 457+\text { VQA: } 257+ \\
\text { VA: } 6=719 € / \text { ha }\end{array}$ \\
\hline
\end{tabular}




\section{CUADRO 1 (CONT.)}

\section{Trabajos sobre valoración de arbolado en España}

\begin{tabular}{|c|c|c|c|c|}
\hline Autor & Utilidad $^{*}$ & Bien/Servicio & Metodología & Valor \\
\hline Campos y Riera (1996) & $\mathrm{Fo}, \mathrm{Me}^{1}$ & $\begin{array}{l}12 \text { encinares y } 3 \text { alcorno- } \\
\text { cales (Península Ibérica) }\end{array}$ & $\begin{array}{l}\text { Tasa real de rentabilidad } \\
\text { privada } \\
\text { Componente ambiental } \\
\text { (Coste del Viaje y Valora- } \\
\text { ción Contingente) }\end{array}$ & $\begin{array}{l}\text { TIR }=3,6 \% \\
\text { Rentabilidad ambiental mínima para } \\
\text { el propietario }=39,6 € / \text { ha }\end{array}$ \\
\hline \multirow[b]{2}{*}{ Caparrós et al. (2001) } & \multirow[b]{2}{*}{ Fo, $\mathrm{Me}^{1}$} & \multirow[b]{2}{*}{$\begin{array}{l}\text { Pinus sylvestris } L \\
\text { Sierra de Guadarrama }\end{array}$} & Sistema CAF & Renta total $=335,08 € /$ ha \\
\hline & & & \multicolumn{2}{|c|}{$\begin{array}{l}\text { Componentes ( } € / \text { ha): Madera: } 168,61 \text {; Pastos: } 10,92 \text {; Caza: 0,261; } \\
\text { Hongos: } 21,39 \text {; Recreativo: } 142,16 \text {; Carbono: } 0,582 \text {; } \\
\text { Conservación: } 29,37\end{array}$} \\
\hline Caparrós et al. (2007) & Fo, $\mathrm{Me}$ & $\begin{array}{l}\text { P.N. los Alcornocales. } \\
\text { Fijación } \mathrm{CO}_{2} \text { comparando } \\
\text { forestación con alcornoque } \\
\text { o eucalipto }\end{array}$ & $\begin{array}{l}\text { Carbon Flow Method (CFM) } \\
\text { (TYAM). En CFM increment } \\
\text { eucalipto. Lo contrario ocurre } \\
\text { con eucalipto afecta negativa } \\
\text { considerar valores de biodive } \\
\text { alcornoque (se recomienda us } \\
\text { por TYAM. }\end{array}$ & $\begin{array}{l}\text { y Ton Year Accounting Method } \\
\text { to superficie forestal básicamente de } \\
\text { al emplear TYAM. La reforestación } \\
\text { amente al bienestar de los visitantes. Al } \\
\text { ersidad-paisajísticos aumenta superficie } \\
\text { so de CFM). En caso contrario se opta }\end{array}$ \\
\hline Cardells (1997) & Fo, $\mathrm{Me}^{1}$ & Montes C. Valenciana & Valor por restitución & $16.708,14 € / \mathrm{ha}$ \\
\hline Casas (2001) & $\mathrm{Fo}^{1}$ & Hongos & $\begin{array}{l}\text { Valor de la producción de } \\
\text { trufas con quercíneas mico- } \\
\text { rrizadas (capitalización) }\end{array}$ & $3.000 € /$ ha y año \\
\hline Castilla (1994) & Fo, $\mathrm{Me}^{1}$ & $\begin{array}{l}\text { Montes de Canarias } \\
\text { (laurisilva y pinar) }\end{array}$ & $\begin{array}{l}\text { Producción forestal } \\
\text { Captación agua (valorada } \\
\text { por incremento) }\end{array}$ & $\begin{array}{l}\text { 15.025,3 } € / \text { año }-18.030,4 \text { €/año } \\
89.851 .309,6 \text { €/año }\end{array}$ \\
\hline Chueca (1994) & Or & Norma Granada & $\begin{array}{l}\text { Informatización Norma } \\
\text { Granada }\end{array}$ & Programa VALARB \\
\hline Coll (1991) & $\mathrm{Fr}$ & $\begin{array}{l}\text { Daños cosecha de cítricos } \\
\text { en la provincia de Castellón }\end{array}$ & $\begin{array}{l}\text { Funciones dosis-respuesta. V } \\
\text { Función Daños: } \\
\text { 1) Relación emisión de partíc } \\
\text { No significativa. } \\
\text { 2) Relación generación de en } \\
\text { Significativa. } \\
\text { 3) Relación generación de en } \\
\text { Significativa. }\end{array}$ & $\begin{array}{l}\text { Talor daño total (1980-1991). Cálculo } \\
\text { culas ácidas y rendimientos de cítricos: } \\
\text { nergía eléctrica y devaluación cosecha: } \\
\text { nergía eléctrica y manchado de fruta: }\end{array}$ \\
\hline Constant (1999) & $\mathrm{Or}^{2}$ & Jardín Botánico Valencia & Norma Granada & 40,7 millones $€$ (202 ejemplares) \\
\hline De la Maza et al. (1978) & $\mathrm{Fo}^{1}$ & Monte en pie & $\begin{array}{l}\text { Factores (coeficientes) a valo } \\
\text { pendientes, obstáculos, estad } \\
\text { trabajo; } 2 \text { ) Características de } \\
\text { y diámetro; } 3 \text { ) Gestión del mo } \\
\text { árboles en pie y superficie; 4) } \\
\text { bilidad, distancia saca, conve } \\
\text { vía principal. }\end{array}$ & $\begin{array}{l}\text { orar: 1) Correspondientes a la estación: } \\
\text { lo del terreno, precipitación y época de } \\
\text { la masa: especie, ramosidad, volumen } \\
\text { onte: tratamientos, densidad de cortas, } \\
\text { Infraestructuras: mecanización, accesi- } \\
\text { ersión, distancia transporte interior y por }\end{array}$ \\
\hline Díaz (1998b) & $\mathrm{Fo}^{1}$ & $\begin{array}{l}\text { Especies forestales } \\
\text { de crecimiento medio } \\
\text { y lento }\end{array}$ & $\begin{array}{l}\text { Tasas de descuento: conceptu } \\
\text { nes en el sector forestal españ } \\
\text { su estimación. }\end{array}$ & $\begin{array}{l}\text { ualización, repaso a las tasas más comu- } \\
\text { ñol (1982-1997) y recomendaciones para }\end{array}$ \\
\hline Díaz et al. (2003) & Fo & $\begin{array}{l}\text { Producción fúngica en } \\
\text { Monte Urcido (Zamora) }\end{array}$ & $\begin{array}{l}\text { Programación lineal: inte- } \\
\text { gración producción micoló- } \\
\text { gica en modelos de gestión } \\
\text { forestal. }\end{array}$ & $\begin{array}{l}\text { VAN producción setas }>25 \% \text { VAN } \\
\text { producción de madera }\end{array}$ \\
\hline
\end{tabular}




\section{CUADRO 1 (CONT.)}

\section{Trabajos sobre valoración de arbolado en España}

\begin{tabular}{|c|c|c|c|c|}
\hline Autor & Utilidad $^{*}$ & Bien/Servicio & Metodología & Valor \\
\hline Díaz y Bravo (2002) & Fo, $\mathrm{Me}^{1}$ & $\begin{array}{l}\text { Pinus sylvestris } L . \\
\text { (Alto Ebro) }\end{array}$ & \multicolumn{2}{|c|}{$\begin{array}{l}\text { Valor esperado del suelo (VES) vs. green tree retention (GTR) } \\
\text { VES del manejo tradicional se equipara a alternativas que incorporen } \\
\text { un } 25 \% \text { de GTR (calidad } 17 \mathrm{~m} \text { a los } 100 \text { años) o un } 50 \% \text { de GTR (ca- } \\
\text { lidad } 23 \mathrm{~m} \text { a los } 100 \text { años). }\end{array}$} \\
\hline Díaz y Prieto (2000) & Fo & Montes en España & DAFO & \\
\hline \multirow{3}{*}{ González y Prada (1997) } & \multirow{3}{*}{$\mathrm{Me}^{1}$} & \multirow{3}{*}{$\begin{array}{l}\text { Parque Natural del Monte } \\
\text { Aloia (Galicia) } \\
\text { Valoración contingente }\end{array}$} & $\begin{array}{l}\text { Valor actual } \\
\text { para los visitantes }\end{array}$ & $489.570,5 €-713.191,9 €$ \\
\hline & & & $\begin{array}{l}\text { Valor con especies distintas } \\
\text { (frondosas) }\end{array}$ & $119.369,3 €-225.763,6 €$ \\
\hline & & & Valor de existencia & $1.455 .945,6 €-2.086 .110,7 €$ \\
\hline Guadalajara et al. (1992) & $\mathrm{Or}^{1}$ & $\begin{array}{l}\text { Espacios verdes urbanos } \\
\text { (Valencia) }\end{array}$ & Precios hedónicos & $\begin{array}{l}\text { Elevada correlación entre el precio } \\
\mathrm{m}^{2} \text { de la vivienda y el número de ár- } \\
\text { boles por distrito (nivel significación } \\
0,998 \text { ). }\end{array}$ \\
\hline Hernández (1994) & $\mathrm{Me}$ & $\begin{array}{l}\text { Explotación de biomasa } \\
\text { residual (combustible) }\end{array}$ & \multicolumn{2}{|c|}{$\begin{array}{l}\text { Beneficio Comercial }(\mathrm{BC}) \text {. Beneficios ambientales (BA): tasa } \\
\text { ecológica. } \\
\mathrm{BC}>0 \text { entre } 0-18 \text { años; BC (con BA) }>0 \text { entre } 0-32 \text { años. } \\
\text { BC (considerando parte de los costes de recogida de biomasa como } \\
\text { mantenimiento de sistemas agroforestales) }>0 \text { entre } 0-47 \text { años. }\end{array}$} \\
\hline López-Peredo et al. (2009) & Fo, $\mathrm{Me}^{1}$ & $\begin{array}{l}\text { Superficie forestal provincia } \\
\text { de Segovia }\end{array}$ & $\begin{array}{l}\text { Madera: métodos analíticos } \\
\mathrm{CO}_{2} \text { capturado }(I A V C)\end{array}$ & $\begin{array}{l}19,53 € / \text { ha }(10.162 .870,3 €) \\
48,29 € / \text { ha }(12.973 .851,3 €)\end{array}$ \\
\hline Martínez (2008) & Fo & Comarca Pinares (Soria) & $\begin{array}{l}\text { VAN Boletus edulis (grupo) } \\
\text { VAN Lactarius grupo } \\
\text { deliciosus }\end{array}$ & $\begin{array}{l}2,1 \text { mill. } € / \text { año } \\
1,7 \text { mill. } € / \text { año }\end{array}$ \\
\hline Martínez (2002) & Fo, $\mathrm{Me}^{1}$ & $\begin{array}{l}\text { Montes en La Almoraima } \\
\text { (Cádiz), Pinar de Valsaín } \\
\text { (Segovia) y Río Madera de } \\
\text { Segura de la Sierra (Jaén) }\end{array}$ & \multicolumn{2}{|c|}{ 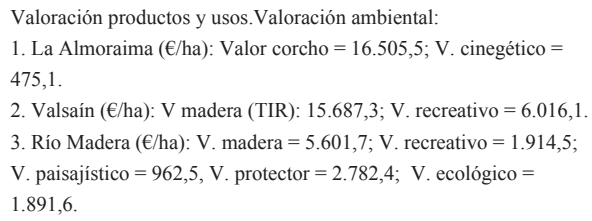 } \\
\hline $\begin{array}{l}\text { Medina y Prieto (2004) y } \\
\text { Medina (2006a y b) }\end{array}$ & $\mathrm{Me}^{1}$ & $\begin{array}{l}\text { Ecosistemas urbanos } \\
\text { Madrid }\end{array}$ & \multicolumn{2}{|c|}{$\begin{array}{l}\text { Método de los indicadores: valoración ambiental. } \\
\text { Valor espacios verdes }\left(€ / \mathrm{m}^{2}\right) \text { para distintos municipios, distinguiendo } \\
\text { entre: espacio abierto, parque, jardín, alineación, espacio singular,... }\end{array}$} \\
\hline Mogas y Riera (2001) & $\mathrm{Me}$ & Cataluña & \multicolumn{2}{|c|}{$\begin{array}{l}\text { Impactos forestación sobre la función recreativa, de absorción de } \mathrm{CO}_{2} \\
\text { y de protección erosión: ordenación contingente y experimento de } \\
\text { elección (Disposición a Pagar, DAP). } \\
\text { Mayor DAP (valor absoluto) en métodos de elección que en orde- } \\
\text { nación contingente. }\end{array}$} \\
\hline Montoya (1993) & Fo & Pastos & $\begin{array}{l}\text { Valor del } \mathrm{kg} \text { de cebada en } \\
\text { relación con el de la unidad } \\
\text { forrajera (U.F.) pastoral. }\end{array}$ & $\begin{array}{l}\text { U.F. (rango): } 1,20 \text { Pulpa seca remola- } \\
\text { cha }-0,10 \text { Pasto basto en verde. }\end{array}$ \\
\hline Muñoz y Riera (1994) & $\mathrm{Fo}, \mathrm{Me}^{1}$ & $\begin{array}{l}\text { Bosque Pallars Subirà } \\
\text { (Pirineo Catalán) }\end{array}$ & $\begin{array}{l}\text { Rentabilidad privada espe- } \\
\text { cies arbóreas } \\
\text { Rentabilidad social (valor } \\
\text { recreativo; v. contingente) }\end{array}$ & $\begin{array}{l}\text { Mayor TIR en especies con cre- } \\
\text { cimiento rápido. Si se incorporan } \\
\text { ayudas + fiscalidad aumenta la ren- } \\
\text { tabilidad, favoreciendo especies de } \\
\text { crecimiento lento (roble y encina) } \\
75 € / \text { visitante. }\end{array}$ \\
\hline
\end{tabular}




\section{CUADRO 1 (CONT.)}

\section{Trabajos sobre valoración de arbolado en España}

\begin{tabular}{|c|c|c|c|c|}
\hline Autor & Utilidad $^{*}$ & Bien/Servicio & Metodología & Valor \\
\hline Mutke et al. (2000) & Fo, $\mathrm{Me}^{1}$ & $\begin{array}{l}\text { Forestaciones pino piño- } \\
\text { nero. Tierra de Pinares } \\
\text { (Valladolid) }\end{array}$ & $\begin{array}{l}\text { Rentabilidad comercial } \\
\text { privada de plantaciones } \\
\text { tradicionales y de plantas } \\
\text { injertadas de pino piñonero: } \\
\text { VAN (metodología FPO). }\end{array}$ & $\begin{array}{l}\mathrm{VAN}_{\text {Pino injertado }}=10.845,8-17.086 € / \mathrm{ha} \\
\mathrm{VAN}_{\text {Pino sin injertar }}=2.744,5-4.570,1 € / \mathrm{ha}\end{array}$ \\
\hline Ortuño y Jovellar (1996) & $\mathrm{Fo}^{1}$ & Encinar adehesado & $\begin{array}{l}\text { Conversión de producción } \\
\text { en unidades alimenticias } \\
\text { con valor de mercado. }\end{array}$ & $120,20 € / \mathrm{ha}$ \\
\hline Ovando et al. (2006) & $\mathrm{Fo}, \mathrm{Me}^{1}$ & $\begin{array}{l}\text { Dehesa Monfragüe (DM, } \\
\text { Cáceres), Macizo del Aljibe } \\
\text { (MA, Cádiz-Málaga) y Ma- } \\
\text { cizo de las Gavarras (MG, } \\
\text { Gerona) }\end{array}$ & $\begin{array}{l}\text { Sistema CAF, valores pre- } \\
\text { sentes descontados y ACB. } \\
\text { Rentas de Capital a precio } \\
\text { de mercado }\left(\mathrm{RC}_{\mathrm{pm}}\right) \text { y a } \\
\text { coste de los factores }\left(\mathrm{RC}_{\mathrm{cf}}\right) \\
\text { Renta Total Sustentable } \\
\left(\mathrm{RTS}_{\mathrm{pm}}\right)\end{array}$ & $\begin{array}{l}\mathrm{MA}(€ / \mathrm{ha}): \mathrm{RC}_{\mathrm{pm}}=382 ; \mathrm{RC}_{\mathrm{cf}}=501 \\
\mathrm{DM}(€ / \mathrm{ha}): \mathrm{RC}_{\mathrm{pm}}=417 ; \mathrm{RC}_{\mathrm{cf}}=446 \\
\mathrm{MG}(€ / \mathrm{ha}): \mathrm{RC}_{\mathrm{pm}}=326 ; \mathrm{RC}_{\mathrm{cf}}=427 \\
\mathrm{RTS}_{\mathrm{pm}} \mathrm{MA}=720 € / \mathrm{ha} ; \mathrm{RTS}_{\mathrm{pm}} \mathrm{DM}= \\
620 € / \mathrm{ha} ; \mathrm{RTS}_{\mathrm{pm}} \mathrm{MG}=535 € / \mathrm{ha}\end{array}$ \\
\hline Ovando et al. (2008) & $\mathrm{Fo}, \mathrm{Me}^{1}$ & $\begin{array}{l}\text { Pinus Pinea } \text { L en Viana y } \\
\text { Páramo (Valladolid) }\end{array}$ & $\begin{array}{l}\text { Rentabilidad forestación de ti } \\
\text { piñonero (piñones vs. madera } \\
\text { también la fijación } \mathrm{CO}_{2} \text {. } \\
\text { Dadas las actuales ayudas púl } \\
\text { rentable sólo en Páramo y cor } \\
\text { baja. La inclusión fijación CC } \\
\text { mico, incluso con alta intensi } \\
\text { ción preferente de piña por ár } \\
\text { En Viana la forestación no es } \mathrm{C} \\
\text { pietario un precio superior a } 35\end{array}$ & $\begin{array}{l}\text { erra de cereal en secano con pino } \\
\text { licas, esta forestación es una alternativa } \\
\text { una intensidad de claras moderada y } \\
{ }_{2} \text { en Páramo aumenta interés econó- } \\
\text { lad de claras para favorecer la produc- } \\
\text { ool individual. } \\
\text { na alternativa, excepto si se pagara al pro- } \\
€ / \mathrm{t} \mathrm{CO}_{2} \text { fijado en la biomasa forestal. }\end{array}$ \\
\hline Reyna y Cardells (1999) & $\mathrm{Me}^{1}$ & Ecosistemas C. Valenciana & $\begin{array}{l}\text { Analytic Hierarchy Process } \\
\text { (AHP) }\end{array}$ & $\begin{array}{l}\text { Pinar: } 6.151,8 € / \text { ha }-8.709,5 € / \text { ha } \\
\text { Encinar: } 13.049,6 € / \text { ha }-18.475,1 € / \text { ha }\end{array}$ \\
\hline Romero (1994) & Fo, $\mathrm{Me}$ & Planificación forestal & $\begin{array}{l}\text { Análisis metodologías multic } \\
\text { forestales. } \\
\text { Descarta enfoques multiatribut } \\
\text { Ventajas de los enfoques decis } \\
\text { compromiso no presenta venta }\end{array}$ & $\begin{array}{l}\text { iterio en la planificación de los recursos } \\
\text { oneducido interés enfoque multiobjetivo. } \\
\text { onasados en metas. Programación } \\
\text { as respecto a la programación por metas. }\end{array}$ \\
\hline Sales (1997) & $\mathrm{Me}$ & $\begin{array}{l}\text { Zonas verdes (Valencia) } \\
\text { Precios hedónicos }\end{array}$ & $\begin{array}{l}\text { En precio medio } \mathrm{m}^{2} \text { vivienda } \\
\text { dotación de } \mathrm{m}^{2} \text { de zona verde } \\
\text { distancia al centro de la ciuda }\end{array}$ & $\begin{array}{l}\text { importancia relativa (correlación) de la } \\
\text { habitante }(0,37) \text {. Mayor importancia } \\
\text { d }(0,75) \text {. }\end{array}$ \\
\hline Salvador (1994) & $\mathrm{Or}^{1}$ & Espacios verdes urbanos & $\begin{array}{l}\text { Valor conjunto: Valor Básico } \\
\text { FC: Objetivos Cualitativos ( } \\
\text { Unidades Geográfico-Ecológ } \\
\text { nerabilidad; Antecedentes Hi } \\
\text { (Atractivo intrínseco; Tipical }\end{array}$ & $\begin{array}{l}\text { (criterios) + Factores Correctores (FC) } \\
\text { aturalidad y Rareza; Situaciones y } \\
\text { cas; Accesibilidad; Fragilidad o Vul- } \\
\text { tóricos) y Subjetivos Cuantificables } \\
\text { dad y Vernacularidad). }\end{array}$ \\
\hline $\begin{array}{l}\text { Vidal (1997) y Caballer } \\
\text { y Vidal (1999) }\end{array}$ & $\mathrm{Or}^{3}$ & $\begin{array}{l}\text { Coníferas, Palmeras } \\
\text { Valoración analógica }\end{array}$ & $\begin{array}{l}\text { La altura de la planta o del trc } \\
\text { elevado de la variabilidad del } \\
\text { les y exponenciales (elevados } \\
\text { tatación de la existencia de ur } \\
\text { cepellón/contenedor aumenta }\end{array}$ & $\begin{array}{l}\text { nco (en } \mathrm{cm} \text { ) explica un porcentaje muy } \\
\text { precio al emplear ecuaciones potencia- } \\
\text { coeficientes de determinación). Cons- } \\
\text { valor de ubicación. La presentación en } \\
\text { el nivel de explicación del modelo. }\end{array}$ \\
\hline Vidal (2003) & $\mathrm{Or}^{2}$ & Palmeral de Orihuela & Norma Granada & $34.043 .302 €$ \\
\hline Vidal et al. (2002) & $\mathrm{Or}^{3}$ & Palmeras & \multicolumn{2}{|c|}{$\begin{array}{l}\text { Valoración analógica } v s \text {. Norma Granada. Valor básico: menor des- } \\
\text { viación cuadrática en valoración analógica (ajuste lineal y potencial) } \\
\text { frente a Norma Granada. }\end{array}$} \\
\hline
\end{tabular}

${ }^{*}$ Fr: Frutal; Fo: Forestal; Me: Medioambiental; Or: Ornamental. ${ }^{1}$ Valoración como masa; ${ }^{2}$ Valoración como individuo;

${ }^{3}$ Valoración de la especie.

Fuente: Elaboración propia. 


\section{Valoración de la utilidad frutal}

Atendiendo a la componente frutal del arbolado, Aznar et al. (2002) plantean una metodología de valoración de plantaciones, donde el valor del arbolado se calcula independientemente, considerando éste como una inversión. Los autores capitalizan la ganancia de la plantación a una tasa calculada como la resultante de restar a la rentabilidad media de la deuda pública la tasa media de inflación. Esta tasa incluiría una prima de riesgo mínima, obtenida como el producto del ratio prima de rentabilidad/ riesgo del mercado bursátil por el riesgo de la plantación a valorar. Dicha metodología se aplica a las principales variedades de cítricos de la Comunidad Valenciana en el período 1986/1996, obteniendo primas de riesgo entre el 2,7 y el 10,4\% y tasas de actualización entre el 7,3 y el 14,98\%.

Coll (1991) valora, mediante la estimación de funciones dosis-respuesta, los efectos producidos por la contaminación atmosférica causada por una central térmica en plantaciones de cítricos, variaciones tanto en calidad como en cantidad de cosecha.

Por su parte, Jurado et al. (2002) analizan la valoración de plantaciones agrícolas, en particular la determinación de la depreciación que como cualquier otro elemento de inmovilizado sufren las plantaciones, así como los problemas que surgen a la hora de realizar las correcciones valorativas pertinentes.

\section{Valoración de la utilidad forestal}

En el caso de la valoración desde la perspectiva forestal, los trabajos clásicos se centraban en la valoración del aprovechamiento maderero, sin olvidar la producción de resina o corcho, pudiendo citar obras como las de Paniagua (1847), Olazábal (1883) o Mackay (1944). Entre alguna de las obras más recientes cabría reseñar las de Esteban (1979), Arenas (2000), Martínez (2000) u Ortuño et al. (2007).

Un concepto de gran importancia en valoración forestal es el de turno. Díaz (1997) hace una profunda revisión del concepto de turno forestal económicamente óptimo, considerando, por un lado, sólo aquellos trabajos que contemplan los bosques como productores de madera, conocida como solución de Fautsmann, sin tener en cuenta otras producciones y/o externalidades. Por otro lado, estudia también cómo se puede modificar la solución de Fautsmann considerando los bosques como entes productores de múltiples bienes y servicios (Díaz, 1998a). Interesante es también el trabajo de Casals (2005), donde se analizan la generalización del concepto de turno forestal, la propiedad de los montes y la introducción de la fórmula de Faustmann en España en el período 1849-1918, aportando varios casos prácticos de economía y valoración forestal, así como una referencia explícita y práctica a la traducción que en 1972 realiza Francisco de Paula Arrillaga de la obra de Heyer (1862).

Por su parte, De la Maza et al. (1978) proponen un método de valoración de un monte en pie desde una perspectiva exclusivamente maderera, diferenciando entre aquellos factores que pueden tener incidencia en el valor final, estableciendo para cada uno de ellos divisiones según su incidencia en el resultado final. 
Por otro lado, Díaz y Romero (1995) se plantean una serie de reflexiones de política forestal a la hora de calcular la rentabilidad económica de diferentes especies arbóreas de crecimiento medio y lento. Por su parte Díaz (1998b) trata de conceptualizar la tasa de descuento en la gestión agroforestal, describiendo su influencia en ciertas decisiones forestales. Analiza también las tasas de descuento empleadas comúnmente en el sector forestal español, con especial detenimiento en el período 1982-1997, estableciendo finalmente una serie de recomendaciones a la hora de su estimación.

La valoración de montes arbolados es abordada por Prieto et al. (1998 y 1999) en sendos artículos. En una primera parte (1998) se revisan los métodos empleados en la valoración forestal, atendiendo exclusivamente a los aspectos productivos del monte (principalmente la madera), definiendo los tipos, fines y factores de esta valoración. También revisan los métodos empleados y los tipos de valoración que se pueden suscitar atendiendo al ámbito y a las diferentes formas de masa que se suelen presentar. La segunda parte de su trabajo (1999) se dedica a presentar los diferentes métodos de valoración de aquellos bienes y servicios producidos en los montes, y que a diferencia de otros outputs (e.g., madera, frutos, etc.) no disponen de un precio de mercado. Asimismo, estudian los distintos intangibles que se pueden separar en una valoración forestal y citan ejemplos concretos de su aplicación en España y otros países.

La problemática sobre la valoración de los montes en España es abordada por Díaz y Prieto (2000) mediante un análisis DAFO donde se analizan las aplicaciones de la valoración forestal, se clasifican los valores económicos de los montes y se evalúan las posibles técnicas de valoración y su problemática específica.

También en esta línea, Díaz y Bravo (2002) plantean diferentes opciones de gestión silvícola a la hora de valorar ecosistemas forestales, cuestionándose la validez del "valor esperado del suelo" como estimador de las masas forestales. Entre dichas opciones estaría la retención de parte de la masa en la corta final (green tree retention).

Los productos forestales no madereros, salvo excepciones, han estado enmascarados o bien tras la secular preponderancia del output maderero o, actualmente, detrás de otros servicios asociados a las masas forestales. La relación de productos forestales no madereros con un uso consuntivo sería muy larga, incluyendo productos comestibles, suplementos dietéticos y medicinales, partes de árboles, arreglos florales y decorativos, frutos (piñones, castañas, etc.), corcho, resina, hongos (tantos setas como trufas), mimbre, plantas de aprovechamiento farmacéutico, pastos, etc. (Díaz, 2002).

Así, la valoración del pasto, como producto forestal, es abordada por Montoya (1993), proponiendo un sistema de valoración basado en el valor del kilo de cebada puesto en relación con el de la unidad forrajera pastoral en el sistema ganadero establecido, sistema que recomiendan en el caso de pastizales bajo ordenación pública.

La valoración de un ecosistema de gran representatividad en nuestro país, como es el caso de las dehesas, ha sido fruto de diferentes estudios. Campos (1993) valora conjuntamente los valores comerciales y ambientales de una muestra de dehesas españolas, concluyendo que la conservación de sus recursos naturales requiere ayudas financieras públicas. Calvo et al. (1994) analizan su papel como sistema de explotación generador de suelo fértil, valorando cuantitativa y cualitativamente el suelo 
creado y formado anualmente por las deyecciones de los animales en pastoreo libre y la materia seca aportada por las masas herbácea y arbustiva. Se valora económicamente, tanto el humus y los componentes que entran a formar parte de él, como la fertilidad química aportada al suelo por el estiércol animal. La formación de humus se cuantificó en 33,59 €/ha en la dehesa desarbolada y de 102,32 €/ha en la dehesa arbolada. Ortuño y Jovellar (1996) para el caso del encinar adehesado incluyen en la valoración los pastizales, el fruto y la leña como aprovechamientos más representativos. Los resultados económicos se obtienen principalmente a través de la conversión de la producción en unidades alimenticias con valor de mercado. El valor medio resultante, de 120,20 € de margen bruto por hectárea, es comparable al obtenido por otros usos agrarios alternativos a la explotación silvopastoral e incluso superior en muchos casos. Por su parte, Campos y Riera (1996) valoran comercialmente un grupo de dehesas y montados ibéricos, obteniendo una tasa real de rentabilidad privada para los propietarios del 3,6\%. También valoran, por el método del coste del viaje, una componente ambiental mínima para el propietario, estimada en 39,6 €/ ha. En un trabajo complementario, Campos et al. (1996), dentro de la determinación del valor económico total (VET) de la dehesa del Área de Monfragüe, estiman el excedente neto para el caso de una dehesa desarbolada $(8,2-58,6 € /$ ha) y otra arbolada (14,6-65,1 €/ha).

La rentabilidad de las repoblaciones realizadas con alcornoques ha sido objeto de estudio por autores como Aunós (1994) u Ovando et al. (2006), mientras que Ortuño y Jovellar (1997) y Campos (1998a) analizan aspectos económicos más generales de su cultivo. Torres et al. (1994) valoran este sistema multiproductivo centrándose en la producción de corcho, sin olvidar el resto de sus beneficios directos, inmediatamente valorables en términos económicos, e indirectos, de índole ecológica o social.

Diversos trabajos han abordado la rentabilidad de la forestación con pino piñonero. Así, Campos (1998b) analiza la rentabilidad de este tipo de forestación frente a eucalipto en el P.N. de Doñana, obteniendo que ésta sólo es competitiva para tasas de descuento inferiores al 4\%, siendo siempre la rentabilidad de la forestación con pino inferior a la del eucalipto. Mutke et al. (2000) estudian la rentabilidad económica que supone el uso de plantas injertadas para las forestaciones con Pinus pinea en la provincia de Valladolid. Como alternativas, se plantearon el no injertar al reforestar o mantener el cultivo agrícola tradicional. Los resultados mostraron que las plantaciones injertadas resultan plenamente competitivas, incluso más que la cebada. En la misma línea se encuentra el trabajo de Ovando et al. (2008), los cuales analizan la rentabilidad de la forestación de tierras agrícolas marginales con pino piñonero en la provincia de Valladolid, concluyendo que la rentabilidad de esta práctica está estrechamente vinculada a las ayudas comunitarias a la forestación. La inclusión de la fijación de carbono como variable aumenta el interés económico de la forestación.

Por su parte, Martínez (2002) valora productos y usos de los montes de La Almoraima (Cádiz), Pinar de Valsaín (Segovia) y Río Madera (Jaén). Para el primero calcula un valor del corcho de $16.505,5 € /$ ha y un valor cinegético de $475,1 € /$ ha. Para el pinar de Valsaín el valor de la madera (valor a partir de la TIR) asciende a 15.687,3 $€ /$ ha, mientras que en Río Madera el valor de la madera (TIR) es de 5.601,7 €/ha. 
Por su parte, Caparrós et al. (2001) comparan la producción fúngica y la de madera, permitiendo integrar ambas a la hora del manejo forestal por parte de sus gestores. Álvarez et al. (2001) también valoran conjuntamente la producción de madera y setas, determinando que la rentabilidad potencial del recurso fúngico es casi cinco veces superior a la correspondiente al aprovechamiento maderero. Sin embargo, debido a la titularidad pública del monte y a falta de gestión de este recurso, la propiedad no se beneficie prácticamente nada del mismo. Así, la problemática de integración de ambos recursos (maderas y setas) pretende ser salvada por Díaz et al. (2003) mediante la integración de la producción micológica en los modelos de gestión forestal basados en técnicas optimizadoras, en particular los modelos de programación lineal, incluyendo también las componentes recreativas. Díaz (2002) y Díaz et al. (2011), caracterizan económicamente los hongos silvestres comestibles y realizan un análisis de las posibles metodologías a emplear para valorar el aspecto comercial de su producción, planteando diferentes casos: reforestaciones, masas forestales establecidas, etc.

La valoración de la producción fúngica también ha sido abordada por Martínez (2008), el cual analiza la producción de carpóforos en los montes de la comarca de Pinares (Soria), valorando la participación del grupo de los Boletus edulis en 2,1 millones $€ /$ año, mientras que los Lactairus grupo deliciosus suponen un valor añadido neto de 1,7 millones €/año. Por su parte, Casas (2001) valora la producción de trufas con quercíneas micorrizadas en $3.000 € /$ ha y año. Otros trabajos que valoran la forestación con plántulas micorrizadas con micelios de hongos de interés comercial son los de Colinas y Fischer (1999) y Reyna (2000). La valoración de la producción de hongos, conjuntamente con el resto de aspectos comerciales y ambientales, ha sido abordada por Campos y Caparrós (2006 y 2009) y Campos et al. (2008a y 2008b).

\section{Valoración de la utilidad medioambiental ${ }^{1}$}

Muchos de los trabajos anteriores, junto a la utilidad frutal y forestal también valoraban la componente medioambiental o social del arbolado. Entre los trabajos con mayor orientación hacia la vertiente ambiental, Campos (1994a) presenta el sistema agroforestal como un modelo de gestión de los recursos agrarios favorable a la producción ambiental. Realiza una descripción del concepto del VET como medida monetaria de los beneficios comerciales y ambientales de dichos sistemas, valores que ya había abordado en trabajos anteriores (Campos, 1993). En su trabajo analiza el resultado comercial de una repoblación con alcornoques en la Sierra de Cádiz, mostrando la necesidad de compensar la mejora ambiental para hacer ésta posible frente a un uso desarbolado del territorio. Este concepto de VET vuelve a ser aplicado por el mismo autor, en este caso a un conjunto de dehesas y montados de la Península Ibérica, con gran variabilidad en los resultados obtenidos (Campos, 1994b).

\footnotetext{
No se incluyen, por lo general, trabajos sobre valoración de Parques Naturales y otros espacios protegidos, al considerarlos parte de la "Valoración económica de los recursos naturales y ambientales".
} 
En el caso de Muñoz y Riera (1994), éstos plantean una primera aproximación a la valoración social de los bosques de la comarca de Pallars Subirà (Pirineo Catalán), compuesta por una componente de valoración privada, estimada mediante un análisis de rentabilidad privada de distintas especies arbóreas con y sin sector público (impuestos y subvenciones) y para distintos precios de la tierra. Obtenían, que en general, las especies de rápido crecimiento eran más rentables que las de rotación larga. Sin embargo, al considerar la política de ayudas de la Unión Europea (UE) se favorecía a las especies más duraderas. La otra componente de ese valor social, externa al propietario forestal, sería la estimación de los beneficios ambientales, calculados en este caso mediante el método de valoración contingente, que ascendía a $75 € /$ visitante.

Por su parte, Hernández (1994) a la hora de valorar la explotación de biomasa residual de un sistema agroforestal adopta un mecanismo alternativo al VET. Considera, por ejemplo, la existencia de una tasa ecológica proporcional al coste de extracción energético del combustible o la suposición que la explotación de la biomasa residual se contemple como una actividad complementaria de otra principal, como sería la práctica preventiva del sistema agroforestal contra incendios.

Castilla (1994) valora los beneficios ambientales de los montes de Canarias desde la perspectiva de la economía ecológica como contrapuesta a la economía convencional o a la economía de los recursos naturales. Determina nueve funciones ambientales para los montes, concluyendo que sólo dos de ellas pueden ser evaluadas de una forma razonable: la productiva y la de captación de agua. La primera la estima entre los 15.000 y los $18.000 €$ al año, mientras que la captación de agua, valorada por incremento, la estima en cerca de 90 millones $€$ al año.

Por otra parte, Romero (1994) analiza la planificación de los recursos forestales bajo el prisma de la metodología multicriterio, dado que los espacios forestales son sistemas que pretenden alcanzar objetivos de naturaleza muy diversa: económicos, ambientales, sociales, etc.; objetivos que usualmente entran en conflicto. Estudia los diferentes métodos multicriterio en el campo forestal, concluyendo en la superioridad de los enfoques satisfacientes basados en metas para problemas de gestión forestal y de la programación compromiso para problemas de valoración de activos forestales.

La valoración del uso recreativo-paisajístico, en este caso del Monte Aloia (Galicia), es abordada por González y Prada (1997). Estos autores valoran dicho uso mediante valoración contingente, para tres escenarios. El primero sería el valor actual para sus visitantes, con resultados que oscilan entre los 489.570,5€ y los $713.191,9 €$. El segundo tendría una composición de especies distinta a la actual, en este caso, un escenario con predominio de frondosas, lo que llevaría a valores entre $119.369,3 €$ y $225.763,6 €$. Por último se planteó un valor de existencia, que oscilaba entre 1.455.945,6€ y 2.086.110,7€.

En el caso de Cardells (1997) y Cardells y Reyna (1998) se plantean directamente la pregunta: ¿Cuánto valen los montes valencianos?, valorándolos desde dos perspectivas diferentes: valoración por restitución y valoración contingente. El valor medio obtenido fue de $16.708,14 € /$ ha, cifra considerada por los autores como muy por encima de los precios de mercado, atribuyendo dicha diferencia a un fallo 
de mercado. Concluyen que el valor de dichos montes debería buscarse a través de las externalidades positivas que aportan a la sociedad. Estos mismos autores también aplican la metodología multicriterio, en este caso el método AHP (Analytic Hierarchy Process), a la valoración integral de los ecosistemas forestales de la Comunidad Valenciana. Distinguen siete ecosistemas diferentes, entre los que se encontrarían el pinar y el encinar. Los valores obtenidos para el pinar oscilan entre los $6.150 \mathrm{y}$ $8.710 € /$ ha, mientras que en el encinar se encuentran entre 13.000 y $18.500 € /$ ha. Sin embargo, los autores advierten que habría que afinar los criterios de selección de los ecosistemas de referencia, ya que las diferencias encontradas en el valor ambiental son relativamente significativas, del orden del 30\% (Reyna y Cardells, 1999).

Por su parte, Almansa y Calatrava (2001) valoran los efectos de un proyecto de restauración hidrológico forestal en la cuenca de Aljibe en Lubrín (Almería). Los resultados muestran que la valoración contingente asigna una mayor rentabilidad social al proyecto, 5,23\% de TIR, frente al valor de las metodologías clásicas, fundamentalmente el coste de reposición, del 2,25\%. Los autores incluyen en el análisis coste-beneficio el criterio de equidad intergeneracional, lo que les lleva a sugerir la necesidad de realizar ajustes a la baja en la tradicional tasa social de descuento. Mogas y Riera (2001) valoran el impacto de una forestación sobre la función recreativa, de absorción de carbono y de protección frente a la erosión de los bosques en Cataluña, comparando la ordenación contingente con los experimentos de elección. Obtienen una mayor disposición a pagar, en valor absoluto, en métodos de elección que en ordenación contingente.

Martínez (2002), junto a la valoración de productos y usos de diferentes montes, incorpora una componente ambiental. En el caso del pinar de Valsaín estima su valor recreativo en 6.016,1 €/ha, mientras que para el río Madera (Jaén) su valor recreativo es de $1.914,5 € /$ ha, su valor paisajístico de $962,5 € /$ ha, su valor protector de $2.782,4 €$ y su valor ecológico de 1.891,6 €/ha.

Por otra parte, Medina y Prieto (2004) y Medina (2006a y 2006b) aplican el método de los indicadores a la valoración ambiental de los ecosistemas urbanos de Madrid, calculando para distintos municipios el valor de sus espacios verdes $\left(€ / \mathrm{m}^{2}\right)$, distinguiendo entre espacios abiertos, parques, jardines, alineaciones y espacios singulares.

La fijación de carbono es abordada por Caparrós et al. (2007), comparando una forestación de alcornoque y otra de eucalipto para el P.N. los Alcornocales. Emplean para ello el Carbon Flow Method (CFM) y el Ton Year Accounting Method (TYAM). En el CFM el incremento en la superficie forestal es básicamente de eucalipto, lo contrario que ocurre cuando se recurre al TYAM. Los visitantes coinciden en señalar que la reforestación con eucalipto afecta negativamente a su bienestar. En el caso de considerar valores de biodiversidad o paisajísticos se incrementaría considerablemente la superficie de alcornoque, recomendando los autores en este caso el uso del CFM.

También López-Peredo et al. (2009) valoran la producción de madera y de captura de carbono, en este caso para la superficie forestal de la provincia de Segovia, integrando estos valores en una base cartográfica. Valoran la madera por métodos analíticos, en función de la especie dominante, con valores promedio de 19,53€/ha $\mathrm{y}$ un valor total de la producción de $10.162 .870,3 €$. En cuanto a la captura de $\mathrm{CO}_{2}, \mathrm{y}$ 
a partir del incremento anual de volumen con corteza, supone un valor promedio de $48,29 € /$ ha y un valor conjunto de 12.973.851,3€. El desarrollo de una metodología que incluya, entre otras, el desarrollo de un SIG que muestre datos económicos o aplicaciones informatizadas del sistema de cuentas agroforestales en los montes de Andalucía se muestra en Guzmán et al. (2009). Los autores plantean medir el VET de los sistemas agroforestales y el desarrollo de sistemas de cuentas necesarias para poder integrar todos los valores económicos de los montes en un futuro sistema de contabilidad verde a escala de la UE.

Por su parte, Caparrós et al. (2001), Campos y Caparrrós (2006; 2009), Campos et al. (2008a y 2008b) y Campos (2010) abordan mediante el sistema de cuentas agroforestales (CAF) la valoración de la renta total social y ambiental de los montes y los ecosistemas forestales, profundizando en la medición de la renta de bienestar del uso múltiple de los bosques expuesta en trabajos anteriores (Campos, 1999).

Un capítulo a parte requeriría la valoración de pérdidas por incendios forestales y la problemática que lleva aparejada, objeto de gran cantidad de trabajos y que aquí se aborda muy someramente. Es claro que este tipo de desastres causan tanto pérdidas medioambientales, como forestales, frutales y ornamentales. En nuestro caso, se ha considerado dentro de la utilidad medioambiental por su influencia en la generación de carbono y la problemática actual del cambio climático y de la emisión de gases de efecto invernadero, sin olvidar otros efectos de impacto ambiental como la pérdida de valores ecológicos, protectores, paisajísticos, recreativos o sociales.

Así, a finales de los años sesenta del siglo XX se desarrollaron fórmulas de valoración de pérdidas por incendios forestales por el antiguo Instituto Forestal de Investigaciones y Experiencias, adaptadas por la Sección de Incendios Forestales del Ministerio de Agricultura, incluyendo también poco después las denominadas "pérdidas en servicios" (Victory y Sáez, 1969 y 1972; Vélez, 1974). En 1982 se publica por parte del Instituto para la Conservación de la Naturaleza (ICONA, 1982) un manual de valoración de pérdidas por incendios forestales, de gran aceptación y utilización. Éste, es fruto de una revisión en 1990, siendo sustituido definitivamente en 1996 por el manual elaborado por Martínez (1996), que conserva gran parte de los criterios que éste presentaba, ampliándose a la estimación del impacto ambiental de los incendios forestales. Otras obras que abordan esta problemática serían, sin ánimo de ser exhaustivos, las de Martínez y Martínez-Chamorro (1996), Vélez (2000), Jiménez (2006) u Ortuño y Fernández-Cavada (2007).

\section{Valoración de la utilidad ornamental}

Por último, queda la componente ornamental, el árbol por su papel decorativo, paisajístico, tanto a nivel privado como público, jugando cada vez mayor importancia la componente vinculada a su valoración en el entorno urbano. En España esta componente se desarrolla más tardíamente, con un primer exponente en el trabajo del ICONA, el cual hace ya más de 35 años publicó una metodología de valoración del 
arbolado ornamental (López y del Álamo, 1975²) inspirada en los métodos anglosajones y suizos, con algunas aportaciones nacionales (López y Ramos, 1969). Estaba basada en la elaboración de seis índices cuyo producto expresaba la cuantía de la indemnización por pérdida de valor ornamental. Estos índices eran: a) clasificación por especies y variedades; b) valor estético y funcional y estado sanitario; c) situación; d) rareza; e) singularidad; f) relación (edad²/diámetro). También se aportaba una metodología de valoración de daños por heridas en el tronco, pérdida de ramas o de raíces.

Poco más de un lustro después, el Ministerio de Obras Públicas y Urbanismo (MOPU, 1982), adaptando el método finlandés de valoración, opta también por un método de valoración multiplicativo a la hora de la tasación de árboles en zonas verdes urbanas. Los índices a considerar para cada árbol eran: a) superficie del árbol; b) valor básico por especie; c) ubicación; d) estado vegetativo.

El método ICONA no contemplaba un gran número de especies de palmeras, amén de que las trata como un árbol dicotiledóneo, lo que suponía posteriores correcciones de su valor y por tanto ciertas cotas de subjetividad. Esto lleva a Palomares (1987) a elaborar un método que permite la transposición de palmeras, de cada palmera, a un valor monetario. Los índices aplicados se agrupan en dos bloques. El primero de ellos hace referencia a los índices de proporcionalidad geométrica, en este caso características particulares del individuo objeto de valoración, mientras que el segundo, de índices de proporcionalidad aritmética, serían los relacionados con características ajenas y extrínsecas al árbol. También aporta diferentes opciones para la valoración de individuos de varios tallos, así como para el cálculo de daños parciales.

Por su parte, Espluga (1989) desarrolla modelos para la determinación de un valor básico en función del tamaño de la especie a valorar, mientras Caballer (1989a y 1989b) plantea un modelo de valoración de plantas ornamentales mediante la utilización conjunta del método de los valores objetivo-subjetivo y de los métodos econométricos, en un intento de salvar la componente de arbitrariedad que los procedimientos empíricos aplicados en el sector acarrean. El autor también plantea una metodología de valoración de un jardín completo o un conjunto ornamental, temática que vuelve a abordar en el caso de jardines urbanos (Caballer, 1993).

A finales de los años ochenta, la Asociación Española de Parques y Jardines Públicos (AEPJP), con el apoyo de la UNESCO a través de su programa MAB ("El hombre y la Biosfera"), de la E.T.S. de Ingenieros de Montes de Madrid y de un grupo de especialistas, participan en la elaboración de un método de valoración que vería la luz en 1990 y que pasó a conocerse como Norma Granada. El "Método de Valoración del Arbolado Ornamental. Norma Granada" (AEPJP, 1990) venía a sustituir a los métodos antes referidos. Fue redactada a partir de la puesta en común de los conocimientos y las experiencias de los miembros de la Comisión de Valoración en sus ámbitos de trabajo y de un exhaustivo estudio de los métodos de valoración publicados hasta aquel momento en distintos países.

Este trabajo fue publicado previamente en el "Boletín de la Estación Central de Ecología". Vol. IV, $n^{\circ} 7$. Madrid. 
La Norma nació con la voluntad de ser revisada con periodicidad y con el deseo de ser un instrumento general, válido para la actuación del profesional libre, de los técnicos y responsables de la Administración, de los juristas y de los jueces, etc. Y así ha sido. Multitud de profesionales la han utilizado y la han puesto a prueba, detectando sus fortalezas y debilidades, convirtiéndose en el método oficial de valoración adoptado por muchas administraciones públicas y el más popular y habitual en la valoración de arbolado ornamental en nuestro país. Fruto de la experiencia y del trabajo de varias comisiones la Norma ha sido revisada en dos ocasiones. La primera en 1999, donde sobre la base de aumentar la objetividad del tasador y de reducir los elementos de discrecionalidad en la valoración se confeccionan una serie de fichas. Éstas recogían una amplia gama de variables referentes al estado físiológico general y al estado estético y funcional, representatividad, etc., que se debían cumplimentar como paso previo a la tasación, quedando así cuantificados y más objetivables los factores intrínsecos y extrínsecos. Se proponían nuevas fórmulas para valorar heridas en troncos y raíces, ampliando el catálogo de especies vegetales e incluyendo la valoración de arbustos (AEPJP, 1999). La segunda revisión se realiza en 2006, es corregida en 2007, y presenta como elemento esencial la modificación del procedimiento de obtención del Valor Básico (VB), abandonando el hasta ahora empleado sigmoide de Richards, y calculando dicho valor a partir de un ajuste polinómico de segundo grado que tiene en cuenta el perímetro de la especie y el precio del ejemplar para un tamaño estándar (10-12 cm), manteniendo y ajustando el resto del procedimiento. Se modifica el peso de los factores externos e internos del árbol, que en la versión anterior podía incrementar el VB en un $800 \%$, de manera que la nueva versión estos factores correctores incrementarían, como máximo, en un 50\% el VB. El grueso de la valoración recae, pues, en el actual VB, que según la Norma: "refleja claramente su valor de mercado extrapolado al momento de la valoración y que este valor refleja la antigüedad y singularidad del árbol".

En el devenir de estos veinte años la Norma ha sido objeto de numerosos estudios, análisis y aplicaciones. Constant (1999) valora el arbolado monumental del Jardín Botánico de Valencia, en total 202 ejemplares, para los que estima un valor superior a los 40 millones $€$, mientras Vidal (2003) valora el Palmeral de Orihuela, obteniendo un valor de 34 millones $€$. Otros trabajos a destacar serían los de Salvador (1989), Chueca (1994; 2001), Palomares (1997), Saurí y Chueca (1997; 1998), Gómez (1998), etc.

Los métodos econométricos y la valoración analógica también han sido aplicados a la valoración de arbolado ornamental. Como ya se ha mencionado anteriormente, Caballer (1989a y 1989b) la aplica conjuntamente con la valoración objetiva-subjetiva, Vidal (1997) la aplica al caso de las coníferas, Caballer y Vidal (1999) lo hacen a palmeras, mientras que Vidal et al. (2002) comparan sus resultados con los obtenidos por aplicación de la Norma Granada.

Por último, en cuanto a la valoración de los ecosistemas urbanos, Guadalajara et al. (1992) tratan de valorar espacios verdes urbanos de la ciudad de Valencia a partir del valor de las viviendas colindantes. Establecen, dada su alta significación estadística, que el número de árboles por cada mil habitantes era un indicador real del precio 
unitario por $\mathrm{m}^{2}$ de las viviendas analizadas. Sin embargo, no pudo confirmarse su hipótesis de que la superficie ejecutada de jardines en la zona de estudio era también un indicador del precio de las viviendas. En esta línea, y también en la ciudad de Valencia, Sales (1997) constata que aunque en el precio medio del metro cuadrado de vivienda tiene una importancia relativa la dotación de $\mathrm{m}^{2}$ de zona verde por habitante, tiene mucha mayor importancia la distancia al centro de la ciudad. Por su parte, Salvador (1994) aporta una serie de consideraciones a la hora de valorar un conjunto de árboles que conforman un jardín urbano, distinguiendo entre factores cuantitativos (tamaño, obras, valor rústico o urbanístico, etc.) y cualitativos (naturalidad, rareza, situación, tipo de unidades geográfica-ecológicas, accesibilidad, fragilidad o vulnerabilidad, antecedentes históricos, etc.). También incorpora atributos valorables desde una perspectiva subjetiva, tales como el atractivo intrínseco o su tipicalidad y vernacularidad.

\section{Conclusiones}

Como ha quedado de manifiesto, la valoración de arbolado se ha abordado desde diferentes puntos de vista, en base a las distintas utilidades que proporcionan los árboles. En los estudios que consideran la plantación como explotación destinada a la producción de bienes de consumo en mercados establecidos, creemos que la determinación de las tasas de descuento y el establecimiento de procedimientos normalizados en la valoración pueden ser líneas futuras de trabajo. En el caso de utilidades de carácter público, muy ligadas a la componente medioambiental, conceptos como la renta total social, el valor económico total o la renta ambiental de los espacios agroforestales, seguirán siendo objeto de estudio, al igual que también serán importantes las valoraciones relacionadas con los nuevos productos ahora no comerciales de los bosques, como la valoración de la fijación y de la huella del carbono o los temas relacionados con la biomasa. Por otro lado, será inevitable una revisión y actualización de la metodología de valoración de pérdidas por incendios forestales.

No se ha incidido en la valoración de espacios naturales protegidos, al emplear unas metodologías valorativas que apenas han trascendido del mundo académico a la vida real (profesional), aunque creemos que no se debe renunciar a su uso, pues la sociedad está cada vez más concienciada en la demanda de una mayor calidad ambiental, en la que los árboles juegan un papel esencial. Esta nueva demanda reclama la inclusión de esta componente en la valoración agroforestal, con lo que se debería hacer pedagogía de estas técnicas (valoración contingente, coste del viaje, precios hedónicos, etc.), ampliando la información de forma que su coste de aplicación sea asumible fuera del ámbito estrictamente académico e intentando que las disposiciones legales al respecto las contemple, lo que atraerá a profesionales que hasta el momento no han hecho uso de ellas. 
Por último, será de gran importancia todo lo relacionado con la valoración de las zonas verdes urbanas; con los valores del arbolado urbano: ambientales, ecológicos, paisajísticos, sociales, económicos, etc. En cuanto a la valoración ornamental, y en particular con la Norma Granada, hito importante en la metodología valorativa de este país, una vez consolidada su aceptación, tanto a nivel de práctica profesional como en reconocimiento social, el gran reto es evitar que muera de "éxito". Debemos, entre todos, dotar los recursos necesarios para facilitar la recogida y elaboración de la información necesaria para mantener los coeficientes y fórmulas que ésta emplea, ya que de no ser así, su aplicación conduciría a valores desfasados temporalmente.

\section{Referencias}

Almansa, C. y Calatrava, J. (2001). “Aplicación del método de valoración contingente a la valoración económica de las externalidades generadas en los proyectos de restauración hidrológica forestal". Comunicación presentada al III Congreso Forestal Español, Granada.

Alonso, R. e Iruretagoyena, M.T. (1995). Valoración Agraria. Conceptos. Métodos y aplicaciones. Mundi-Prensa, Madrid.

Alonso, R. y Serrano, A. (2007). Valoración Agraria: Casos Prácticos de Valoración de Fincas. $2^{a}$ edición. Agrícola Española, Madrid.

Álvarez, A., Díaz, L. y Oria, J.A. (2001). "Valoración de la producción conjunta madera-setas. Aplicación al caso de la Carballeda (Zamora)". Comunicación presentada al III Congreso Forestal Español, Granada.

Arenas, S.G. (2000). Tasación y valoración forestal. Tórculo, Santiago de Compostela.

Asociación Española de Parques y Jardines Públicos (1990). Método de valoración del arbolado ornamental. Norma de Granada. Raíces, Madrid.

Asociación Española de Parques y Jardines Públicos (1999). Norma de Granada. Método para valoración de árboles y arbustos ornamentales. A.E.P.J.P., Madrid.

Asociación Española de Parques y Jardines Públicos (2007). Norma de Granada. Método para valoración de árboles y arbustos ornamentales. A.E.P.J.P, Madrid.

Aunós, A. (1994). "Análisis financiero de los proyectos de repoblación con Quercus suber L”. Comunicación presentada al Simposio Mediterráneo sobre Regeneración del Monte Alcornocal, Mérida.

Aznar, J., Ribal, J. y Pérez-Salas, J.L. (2002). "Valoración de plantaciones". Comunicación presentada al I Congreso Internacional de Valoración y Tasación, Valencia.

Ballestero, E. (1991). Economía de la Empresa Agraria y Alimentaria. MundiPrensa, Madrid.

Caballer, V. (1975). Concepto y Métodos de Valoración Agraria. Mundi-Prensa, Madrid. 
Caballer, V. (1985). Valoración Agraria. Teoría y Práctica. Mundi-Prensa, Madrid.

Caballer, V. (1989a). "Modelos para la valoración de plantas ornamentales". Investigación Agraria. Economía, 4(2): 191-208.

Caballer, V. (1989b). "Valutazione economica di piante ornamentale". Genio Rurale, 718: 11-22.

Caballer, V. (1993). "La valutazione stimativa dei giardini nel contesto urbano". En Fusco Girard, L. (Ed.): Estimo ed economia ambientale. Le nuove frontiere nel campo della valutazione. Francoangeli, Milano: 244-258.

Caballer, V. (1999). Valoración de Árboles. Frutales. Forestales. Medioambientales. Ornamentales. Mundi-Prensa, Madrid.

Caballer, V. y Vidal, F. (1999). "Econometric models in palm appraisal”. Acta Horticulturae, 486: 241-246.

Calvo, J.D., Vargas, J.D. y Aparicio, M.A. (1994). “Análisis económico del humus generado en la dehesa". Agricultura y Sociedad, 73: 281-294.

Campos, P. (1993). "Valores comerciales y ambientales de las dehesas españolas". Agricultura y Sociedad, 66: 243-256.

Campos, P. (1994a). "El valor económico de los sistemas agroforestales". Agricultura y Sociedad, 71: 243-256.

Campos, P. (1994b). "Economía de los espacios naturales: El valor económico total de las dehesas ibéricas". Agricultura y Sociedad, 73: 103-120.

Campos, P. (1998a). “Alcornocales del Suroeste Ibérico”. En Marín, F., Santos, J.D. y Calzado, A. (Eds.): Los montes y su historia. Una perspectiva política, económica y social. Universidad de Huelva, Huelva: 245-288.

Campos, P. (1998b). "Rentas comerciales del pino piñonero y del eucalipto en el parque natural de Doñana". En Campos, P. y López, J. (Eds.): Renta y naturaleza en Doñana. A la búsqueda de la conservación con uso. Icaria, Barcelona: 29-78.

Campos, P. (1999). "Hacia la medición de la renta de bienestar del uso múltiple de un bosque”. Investigación Agraria: Sistemas y Recursos Forestales, 8(2): 407-422.

Campos, P. (2010). "Renta total social y capital de un ecosistema natural". Ambienta, 91: 45-54.

Campos, P. y Caparrós, A. (2006). "Social and private total Hicksian incomes of multiple use forests in Spain". Ecological Economics, 57(4): 545-557. http://doi.org/df8n4k

Campos, P., Caparrós, A., Oviedo, J. L. y Ovando, P. (2008a). "La renta ambiental de los bosques". Arbor-Ciencia. Pensamiento y Cultura, 729: 57-69.

Campos, P., Caparrós, A., Oviedo, J. L. y Ovando, P. (2008b). "La renta total social de los montes”. En Campos, P. y Casado, J.M. (Eds.): Gestión del medio natural en la península Ibérica: economía y políticas públicas. Consejo General del Colegio de Economistas de España, Madrid: 13-56. 
Campos, P. y Caparrós, A. (2009). "La integración del valor de cambio de los servicios ambientales en las cuentas verdes de las áreas naturales". Información Comercial Española, 847: 9-22.

Campos, P., De Andrés, R., Urzainqui, E. y Riera, P. (1996). "Valor económico total de un espacio de interés natural. La dehesa de Monfragüe". En Azqueta, D. y Pérez, L. (Eds.): Gestión de Espacios Naturales. La demanda de servicios recreativos. McGraw-Hill, Madrid: 193-215.

Campos, P. y Riera, P. (1996). "Rentabilidad social de los bosques. Análisis aplicado a las dehesas y a los montes ibéricos". Información Comercial Española, 751: 47-62.

Caparrós, A., Campos, P. y Montero, G. (2001). “Applied multiple forest accounting in the Guadarrama pinewoods (Spain)". Investigación Agraria: Sistemas y Recursos Forestales, 1: 91-108.

Caparrós, A., Cerdá, E., Ovando, P. y Campos, P. (2007). Carbon sequestration with reforestations and biodiversity scenic values. Fondazione Eni Enrico Mattei, Mi-

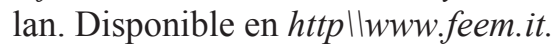

Cardells, F. (1997). “¿Cuánto valen los montes valencianos (I)?” Montes, 48:45-51.

Cardells, F. y Reyna, S. (1998). “¿Cuánto valen los montes valencianos (II)?” Comunicación presentada al III Forum de Política Forestal, Solsona.

Cardells, F. y Salvador, P. (2000). Manual de Valoración de Árboles y Arbustos. Universidad Politécnica de Valencia, Valencia.

Casals, V. (2005). "El turno forestal, la propiedad de los montes y la recepción de la fórmula de Faustmann en España, 1849-1918”. Revista electrónica de Geografía y Ciencias Sociales. IX, 182. Disponible en: http://www.ub.es/geocrit/sn/sn-182.htm

Casas, M. (2001). "Producción de trufas con quercíneas micorrizadas". Revista Forestal Española, 28: 13-18.

Castilla, C. (1994). "Estudio de los beneficios de los ecosistemas forestales de Canarias desde la perspectiva de la economía ecológica". Agricultura y Sociedad, 73: 261-280.

Colinas, C. y Fischer, C. (1999). Cultivo de hongos comestibles micorrícicos. Universidad de Lleida, Lleida.

Coll, J.M. (1991). Evaluación de los efectos producidos por la contaminación atmosférica causada por las centrales térmicas de generación de electricidad en la agricultura de su entorno. Tesis Doctoral. Universidad Politécnica de Valencia, Valencia.

Constant, A. (1999). Estudio y valoración del arbolado monumental del Jardín Botánico de Valencia. Universidad Politécnica de Valencia. Oficina Técnica del Plan Verde del Ayuntamiento de Valencia, Valencia.

Contato, M.L., Ayuga, E. y Grande-Ortiz, M.A. (2008). "A comparative analysis of methods for the valuation of urban trees in Santiago del Estero, Argentina". Spanish Journal of Agricultural Research, 6(3): 341-352.

Chueca, J. (1994). "La aplicación informática de la Norma Granada". En Caballer, V. y Guadalajara, N. (Eds.): Metodología valorativa: Presente y futuro. S.P.U.P.V. Valencia: 337-351. 
Chueca, J. (2001). "La Norma Granada; Un método de valoración económica de los árboles ornamentales. La valoración económica de los árboles ornamentales". Comunicación presentada al II Congreso Iberoamericano de Parques y Jardines Públicos, La Habana.

De la Maza, J., Elvira, L.M. y Pellón, R. (1978). "Valoración de un monte en pie". Montes, 190: 83-101.

Díaz, L. (1997). "El turno forestal económicamente óptimo”. Economía Agraria, 180: 181-224.

Díaz, L. (1998a). "Fundamentos económicos del turno forestal óptimo al incorporar diversos bienes y servicios". Revista Española de Estudios Agrosociales y Pesqueros, 184: 159-182.

Díaz, L. (1998b). "La tasa de descuento en la gestión forestal”. Montes, 54: 49-57.

Díaz, L. (2002). "Valoración de productos forestales no madereros: el caso de los hongos". Comunicación presentada al I Congreso Internacional de Valoración y Tasación, Valencia.

Díaz, L., Alfranca, O. y Voces, R. (2011). "Los hongos silvestres comestibles: una caracterización económica”. Comunicación presentada al VIII Congreso de Economía Agraria, Madrid.

Díaz, L., Álvarez, A. y Oria, J.A. (2003). “Integración de la producción fúngica en la gestión forestal. Aplicación al monte Urcido (Zamora)”. Investigación Agraria: Sistemas y Recursos Forestales, 12(1): 5-19.

Díaz, L. y Bravo, F. (2002). "Influencia de la gestión silvícola en la valoración de montes con especies de crecimiento lento". Comunicación presentada al I Congreso Internacional de Valoración y Tasación, Valencia.

Díaz, L. y Prieto, A. (2000). "Problemática actual de la valoración de montes en España”. Montes, 60: 49-55.

Díaz, L. y Romero, C. (1995). "Rentabilidad económica de especies arbóreas de crecimiento medio y lento: algunas reflexiones de política forestal". Revista Española de Economía Agraria, 171(1): 85-108.

Elorrieta, O. (1947). Valoración de la tierra. Escuela Especial de Ingenieros de Montes, Madrid.

Espluga, A.P. (1989). Valoración de árboles ornamentales. Modelo para la determinación de un valor básico en función del tamaño. Tesis Doctoral. E.T.S.I. Montes, Universidad Politécnica de Madrid, Madrid.

Esteban, E. (1979). Economía de la Empresa Forestal. E.T.S.I. Montes, Universidad Politécnica de Madrid, Madrid.

Gabaldón, R. y Ribal, F.J. (2000). Valoración de árboles. S.P.U.P.V. Colección Papeles de Tasación y Valoración, Valencia.

García, A. (1998). Valoración Inmobiliaria Pericial. Agrícola Española, Madrid.

Gómez, F.J. (1998). "Norma de Granada, apuntes sobre su nacimiento". Comunicación presentada al Congreso de la Asociación Española de Arboricultura, Terrasa. 
González, M. y Prada, A. (1997). "Producción forestal y mercado: valoración económica del monte". Comunicación presentada al II Congreso Forestal Español y I Congreso Forestal Hispano Luso, Pamplona.

Guadalajara, N. (1996). Valoración Agraria. Casos prácticos. 2a edición. MundiPrensa, Madrid.

Guadalajara, N., Gómez, F. y Salvador, P. (1992). "La dotación de árboles y de espacios verdes urbanos, y su relación con los precios de las viviendas en Valencia”. En Caballer, V. y Guadalajara, N. (Eds.): Prospettive della recerca nel settore dell'estimo operativo. Valencia: 183-196.

Guzmán, L., Martín, M.I. y De la Hoz, F.M. (2009). "Valoración económica total y cuentas agroforestales de los montes de Andalucía". Comunicación presentada al $V$ Congreso Forestal Español, Ávila.

Hernández, F. (1994). “Criterios para valorar el balance económico y ecológico de la explotación de biomasa en un sistema agroforestal". Agricultura y Sociedad, 73: 249-260.

Humero, A.E. (2006). Guía Práctica de casos referentes a la edificación y el urbanismo. Dykinson, Madrid.

Heyer, G. (1862). Compendio de Valoración de montes. Imprenta Nacional, Madrid.

ICONA (1982). Manual de valoración de pérdidas por incendios forestales. Instituto para la Conservación de la Naturaleza (ICONA), Madrid.

Jiménez, D. (2006). “¿Cuánto vale un bosque que se quema?” El Mundo. Natura, 5. Disponible: http://www.elmundo.es/suplementos/natura/2006/5/1152183887.html

Jurado, J.A., Martín, M.P. y Domínguez, J. (2002). “Inmovilizados agrícolas: valoración y correcciones valorativas". Comunicación presentada al I Congreso Internacional de Valoración y Tasación, Valencia.

López, M. y del Álamo, C. (1975). El cálculo de indemnizaciones derivadas de la pérdida de árboles ornamentales. ICONA, Madrid.

López, A. y Ramos, A. (1969). Valoración del paisaje natural. Las plantas ornamentales. E.T.S.I. Montes, Universidad Politécnica de Madrid.

López-Peredo, E., Díaz, L. y Voces, R. (2009). “Una aproximación a la valoración de recursos forestales utilizando la cartografía CORINE Land Cover". Comunicación presentada al $V$ Congreso Forestal Español: Montes y Sociedad, Ávila.

Mackay, E. (1944). Fundamentos y métodos de ordenación de montes. Escuela de Ingenieros de Montes, Madrid.

Martínez, E. (1996). Manual de valoración de pérdidas y estimación del impacto ambiental por incendios forestales. Dirección General de Conservación de la Naturaleza. Ministerio de Medio Ambiente, Madrid.

Martínez, E. (2000). Manual de Valoración de Montes y Aprovechamientos Forestales. Mundi-Prensa, Madrid.

Martínez, E. (2002). "Valoración de productos y usos del monte. Valoración ambiental del medio natural". Revista Forestal Española, 31: 7-16. 
Martínez, E. y Martínez Chamorro, E. (1996). "Repercusión de los incendios forestales en la economía local. Pérdidas en valores paisajísticos, recreativos y costes sociales". Montes, 43: 41-44.

Martínez, F. (2008). Producción de carpóforos de macromicetes epigeos en masas ordenadas de Pinus sylvestris L. Tesis Doctoral, E.T.S.I. Montes, Universidad Politécnica de Madrid, Madrid.

Medina, M.J. (2006a). "Valoración ambiental de los ecosistemas urbanos por el método de los indicadores: aplicación en la Comunidad de Madrid". PARJAP, 42: 29-40.

Medina, M.J. (2006b). "Valoración ambiental de los ecosistemas urbanos por el método de los indicadores: aplicación en la C. de Madrid. (Parte II)". PARJAP, 43: 15-27.

Medina, M.J. y Prieto, A. (2004). "El método de los indicadores: un nuevo método de valoración ambiental para ecosistemas urbanos". CT-Catastro, 50: 121-138.

Mogas, J. y Riera, P. (2001). “Comparación de la ordenación contingente y del experimento de elección en la valoración de las funciones no privadas de los bosques". Revista de Economía Agraria y Recursos Naturales, 1(2): 125-147.

Montoya, J.M. (1993). "Determinación del consumo de la carga pastante. Fijación de equivalencias. Valoración del pasto". Montes, 32: 42-46.

MOPU (1982). Diseño y Optimización funcional de las zonas verdes urbanas. Ministerio de Obras Públicas, Madrid.

Muñoz, F. y Riera, P. (1994). "Rentabilidad privada y social de las explotaciones forestales". Agricultura y Sociedad, 73: 121-135.

Museros, T. (1871). Lecciones sobre tasación de tierras y demás objetos del campo. Antonio Molina, Murcia.

Museros, T. (1877). Tratado de tasación de tierras y demás objetos del campo. Librería Cuesta, Madrid.

Mutke, S., Díaz, L. y Gordo, J. (2000). “Análisis comparativo de la rentabilidad comercial de plantaciones de Pinus Pinea L. en tierras agrarias de la provincia de Valladolid". Investigación Agraria: Serie Recursos y Sistemas Forestales, 9(2): 270-303.

Olazábal, L. (1883). Ordenación y Valoración de montes. Imprenta de Moreno Rojas, Madrid.

Olmeda, M., Rivera, L.M., Segura, B. y Martínez, J.L. (1989). Métodos de Valoración Agraria. C.O.I. Agrónomos de Murcia. Cuadernos Técnicos, Murcia.

Ortuño, S.F. y Fernández-Cavada, J.L. (2007). "Evaluación económica de los daños por incendios forestales". Comunicación presentada a la IV International Wildland Internacional Conference, Sevilla.

Ortuño, S.F. y Jovellar, L.C. (1996). "Valoración económica del encinar adehesado". Montes, 44: 22-25.

Ortuño, S.F. y Jovellar, L.C. (1997). "Economía de un alcornocal tipo". Revista Forestal Española, 16: 4-7. 
Ortuño, S.F., Madrigal, A. y González, I. (2007). Apuntes de Valoración Agraria y Forestal. E.U. Ingeniería Técnica Forestal, Universidad Politécnica de Madrid.

Ovando, P., Campos, P. y Montero, G. (2006). “Análisis económico de la forestación con alcornoques en España”. Comunicación presentada a la II Conferencia de AERNA, Lisboa.

Ovando, P., Campos, P., Calama, R. y Montero, G. (2008). "Rentabilidad de la forestación de tierras agrícolas marginales con pino piñonero (Pinus pinea L.) en la provincia de Valladolid". Comunicación presentada a la III Conferencia de AERNA, Palma de Mallorca.

Palomares, J. (1987). El valor ornamental de las palmeras. Ayuntamiento de Valencia, Valencia.

Palomares, J. (1997). "Palmeras y evaluación económica: La Norma Granada. Actualización y ampliación de valores futuribles". PARJAP, 6.

Paniagua, J.M. (1847). Manual de la tasación de montes y bosques. Imprenta de D. Manuel Alvarez, Madrid.

Prieto, A., Díaz, L. y Hernando, A. (1998). "Valoración de montes arbolados (1 parte)". CT-Catastro, 33: 65-82.

Prieto, A., Díaz, L. y Hernando, A. (1999). "Valoración de montes arbolados (2 parte)". CT-Catastro, 36: 37-52.

Reyna, S. (2000). Trufa, truficultura y selvicultura trufera. Mundi-Prensa, Madrid.

Reyna, S. y Cardells, F. (1999). "Valoración AHP de los ecosistemas naturales de la Comunidad Valenciana”. Revista Valenciana d'Estudis Autonómics, 27: 153-177.

Romero, C. (1994). "Aplicaciones de la teoría de decisión multicriterio en la planificación de los recursos forestales". Agricultura y Sociedad, 73: 41-70.

Ruiz, F. (1861). Tasación de tierras o ciencia práctica de tasarlas. Martin Masústegui, Castellón.

Ruiz, F. (1969). Valoración Agraria. Mundi-Prensa, Madrid.

Ruiz, F. (1986). Manual de Valoración Agraria y Urbana. Intervalora, Madrid.

Salazar, Z. (1922). Valoración Agrícola y Catastro. Calpe, Madrid.

Sales, J.M. (1997). "Relación entre el precio del metro cuadrado de la vivienda y la dotación de espacios verdes urbanos en la ciudad de Valencia”. Comunicación presentada a las IV Jornadas de Peritos Tasadores Judiciales, Valencia.

Salvador, P.J. (1989). "A new method of assessing values of amenity trees in urban situation (Norma de Granada)". Comunicación presentada al International Symposium, Cost and benefit and functions of urban cooperation. As, Noruega.

Salvador, P.J. (1994). “Consideraciones sobre la valoración de los espacios verdes: el todo, más allá de la suma del valor de las partes". En Caballer, V., Guadalajara, N. (Eds.): Metodología valorativa: Presente y futuro. SPUPV, Valencia: 403-408.

Sánchez, J. (1915). Valoración agraria. Tasación de fincas rústicas. Gutenberg, Madrid. 
Santi, T. (1952). Valoración de fincas y predios. Dossat, Madrid.

Saurí, A. y Chueca, J. (1997). "Propuesta de valoración de las heridas en el tronco del arbolado ornamental. Revisión de la Norma de Granada". PARJAP, 6.

Saurí, A. y Chueca, J. (1998). "Modificación del actual método de valoración económica de árboles y arbustos ornamentales Norma de Granada". Comunicación presentada al Congreso de la Asociación Española de Arboricultura, Terrasa.

Torrejón, A. (1897). Teoría y práctica de la tasación agrícola. Hijos de J. Cuesta, Madrid.

Torrejón, A. (1935). Economía y Valoración Agrícola, Forestal y Urbana. Agroespañola, Madrid.

Torres, E., Montero, G., Ortega, C. y Cañellas, I. (1994). “Aspectos selvícolas, económicos y sociales del alcornocal”. Agricultura y Sociedad, 73: 137-193.

Vélez, R. (1974). "Efectos económicos, sociales y ecológicos de los incendios forestales". Boletín de la Estación Central de Ecología, 3(5): 3-22.

Vélez, R. (Coord.) (2000). La defensa contra incendios forestales. Fundamentos y experiencias. McGraw-Hill, Madrid.

Victory, J.A. y Sáez, A. (1969). Valoración de pérdidas en los incendios forestales. Instituto Forestal de Investigaciones y Experiencias (I.F.I.E.), Madrid.

Victory, J.A. y Sáez, A. (1972). "Valoración de pérdidas en los incendios forestales". Montes, 164: 103-126.

Vidal, F. (1997). "Los modelos de regresión aplicados a la valoración de arbolado. Un caso particular: Las coníferas". Comunicación presentada a las IV Jornadas de Peritos Tasadores Judiciales, Valencia.

Vidal, F. (2002). "Valoración Agraria III. Métodos modernos". En Del Campo (Ed.): Economía Agraria y Valoración. Universidad Miguel Hernández, Elche: 287-308.

Vidal, F. (2003). "La valoración económica del palmeral de San Antón de Orihuela (Alicante): una primera aproximación”. Comunicación presentada al I Congreso Internacional: El Palmeral de Orihuela, Orihuela.

Vidal, F., Martínez-Carrasco, L. y Sales, J.M. (2001). Valoración de arbolado. Universidad Miguel Hernández, Elche.

Vidal, F., Sales, J.M. y Martínez-Carrasco, L. (2002). "Valoración económica de palmáceas: Norma Granada vs. Valoración Analógica”. Comunicación presentada al I Congreso Internacional de Valoración y Tasación, Valencia.

Vidal, F., Martínez-Carrasco, L., Martín, M.A. y Sales, J.M. (2000). Aplicaciones prácticas de la Valoración Agraria. Limencop, Elche. 
